\title{
From Soil to Oil: The Resistance of the Environment in the Cities of Salt
}

\author{
Abeer Abdulaziz AL-Sarrani \\ English Department, College of Arts and Humanities, Taibah University, Saudi Arabia
}

Received: 17-07-2015

doi:10.7575/aiac.ijclts.v.3n.4p.20
Accepted: 28-08- 2015

Published: $31-10-2015$

\begin{abstract}
This article explores the environment's resistance in the face of “Oil" discovery in Abdel Rahman Munif'snovel the Cities of Salt. Linking the areas of environmentalism, postcolonialism, and Oil discovery, the article claims that Oil is the colonizer which has colonized the environment. The article then shows the environment resistance which is portrayed by Munif indirectly by several episodes of personifying the environment and by the people's nature-like responses and reactions. The article ends up with tracing the people's cultural displacement due to the colonization of their environment.
\end{abstract}

Keywords: Environmentalism, postcolonialism, Petroleum Culture, Ecosystem, Cultural Displacement, Resistance

\section{Introduction}

Rob Nixon in his book titled Slow Violence and the Environmentalism of the Poorasked, "[w]hat would it mean to bring environmentalism into a full, productive dialogue with postcolonialism?" (2011: 233). He further explains the reason for such question through stating that:

These two fields have emerged in recent decades as among the most dynamic areas in literary studies, yet their relationship has been, until very recently, dominated by reciprocal indifference or mistrust.... environmental studies and postcolonial studies have both exhibited an often-activist dimension that connects their priorities to movements for social change. Yet for the most part, a broad silence has characterized environmentalists' stance toward postcolonial literature and theory while postcolonial critics have typically been no less silent on the subject of Environmental literature. What circumstances shaped this mutual reluctance? And what kinds of intellectual initiatives might best deepen an overdue dialogue that is belatedly starting to emerge? (233)

On realizing the need for other intellectual initiatives for setting up a dialogue between postcolonialism and environmentalism, the March (2011) edition of the PMLA journal editor's column was titled "Literature in the Ages of Wood, Tallow, Coal, Whale Oil, Gasoline, Atomic Power, and Other Energy Sources," which examines the relationship between literatureand energy resources. The column reinforces the need to investigate the effect of these energy resources on the environment and accordingly how much it is necessary to have literary works and scholarly articles that discuss such an important topic. One section of the Editor's Column titled "Oil Spills" where Michael Ziser, states that:

[w]e expect literature to name the governing ideologies of an era, whether by announcing them in its narrative and formal contradictions and antinomies or by attempting to puncture them (however incompletely) through formal innovation, subject matter, and so on. It is startling, then, to realize that our fiction of energy surplus appears to be so completely shielded from view as to be hardly named in our literary fictions at all. (324)

However, Ziser names few existing literary works which investigate the effect of the Oil production including Abdulrahman Munif's novel Cities of Salt, which is the only literary work, until now, that specifically investigates the effect of oil discovery and production on the Arabian Gulf states. Ziser states that such literary works are actually "[a]sk[ing] us to acknowledge the connection between the oil age and its problematic surpluses-economic, political, environmental, sexual, aesthetic, and even religious - and to consider the human effects of its eventual passing"(323). Michael k. Walonen also in an article titled "The Black and Cruel Demon and Its Transformations of Space: Toward a Comparative Study of the World Literature of Oil and Place," states that:

In an era in which the discipline of literary studies finds itself seeking to go beyond nationally bounded canons and fields of concern, it is hoped that this approach might provide a productive way of discursively situating texts from disparate cultural and linguistic traditions in terms of their responses to a common global and globalizing situation, one whose ramifications, as the preceding has hopefully shown, are immense (58). 
Indeed, in comparison to the literary texts and articles discussing previous global topics including the spice trade and industrial revolution associated with the coal industry, it could be argued that the Oil encounter has not received yet many literary and critical responses especially its effect on the Arab world and previously colonized countries which many were actually colonized due to the their petroleum wealth.

Furthermore, as Rob Nixon stated earlier that social change has been the most dominant topic for so many articles discussing postcolonial and environmental literature especially those literary works that have been written by writers coming from those previously colonized parts of the world studies on Munif's Cities of Salt validate his statement. Forms of people's social resistance and change have been explored in several articles which have discussed Cities of Salt, which is classified as environmental and postcolonial novel. Some of these articles have argued that the novel is portraying social change. For example, Issa J. Boullata's article titled "Social Change in Munif's Cities of Salt," states that "the society as a whole is the protagonist of this novel, social change being he evolving process which shows how society deals with the antagonistic forces encountered in life" (213). He further enforces his point and cautions that "[t]his is the moral adventure of Munif"s novel, which, if not recognized, may lead the literary critic to unsound judgment because of upset and unwarranted expectations" (213). Ellen McLarney in "Empire of the Machine": Oil in the Arabic Novel" explores how the Arabian Utopia has been ruined by the forces of industrialization. The article mainly focuses on the different social aspects that have taken place in the Arabian Oasis since the establishment of the oil company was viewed as an act of colonialism.

Rob Nixon also claims that "[t]he companion subject of Cities is the growing repression and disillusionment of ordinary Bedouins and their intense, if episodic, insurrectionary response" (73). He further states that Munif "tracks the psychological and cultural disorientation of Bedouins whose lands and lives the two-headed behemoth of empire and petro-despotism has trampled" (73). Thus, the previous articles shed some light on the impact of colonization on the land, the cultural dislocation on the people, and the social change that have taken place while neglecting the environment as a major character.

\section{The Humanization of the Environment}

However, not many articles have directly discussed the presentation of the natural environment as a main character in the novel nor how it displayed its resistance in the face of the Oil which is portrayed as a colonial force by Munif. So, in an effort to contribute to what is still at stake in the literary scholarly field and in answering such questions and calls raised by so many including Rob Nixon, the PMLA journal, and Michael K. Walonen, this article focus on the connection among the three areas of environmentalism, postcolonialism and the Oil discovery. Through investigating some environmental and cultural problematic surpluses that happened in the Arabian Oasis after the Oil discovery portrayed in the Cities of Salt, this article claims that Munif in the Cities of Salt presents the Oil as the colonizer and the environment as the humanized-character who's being colonized which is in contrast with several other articles that view the American company as the colonizer and the Arabs as the ones being colonized. The article specifically, claims that Munif humanizes the environment in the novel and presents its indirect resistance to the Oil colonization of its soil through several episodes of its personification and through its peoples' plant and animal-like responses. To further present the importance of the environment and the negative effect of its destruction on its people, this paper also tracks the people's cultural disorientation as a consequence to their inseparable connection to the humanized- environment that reached the extent of portraying it as their neutering mother-figure.

Munif starts the novel with introducing the environmental setting to the readers through the following nostalgic view:

Wadi al-Uyoun was a phenomenon, something of a miracle, unbelievable to those who saw it for the first time and unforgettable forever after. The Wadi's name was repeated at all stages of a journey, in setting out and returning: "How much longer to Wadi al-Uyoun?" "If we make it to Wadi al-Uyoun, we'll rest up for a few days before going on," and "Where are you, Wadi alUyoun, earthly paradise?. (Citiesof Salt 2)

Not only is the Wadi's name was "repeated at all stages of a journey" in fact it is also repeated throughout the novel by Munif. The Arabic word "Wadi" means "a valley, ravine, or channel that is dry except in the rainy season," in the English translation (Oxford Dictionaries). Thus, the repetition of the term "Wadi" both by the characters in the novel and by Munif the narrator, and the translator's decision to keep it in the English translation of the novel reinforces the importance of the Wadi as a character that stands by its own name.

Munif also stresses the importance of the environment through reinforcing the strong relationship among the people of the Wadi and the other natural environmental surroundings, including the animals and plants, which are also continuously presented throughout the novel. In one of the opening scenes of the novel Munif beautifully describes that:

SHORTLY AFTER DAWN,WHEN THE FIRST LIGHT OF day appeared distinct from the shadows and shone gently above, the wadi was still wrapped in the light of mist left by the night, the moisture wrung from the air, trees, and brook water, and from the breath of people then quietly waking up to begin another day" $(105)^{1}$.

\footnotetext{
${ }^{1}$ Emphasis is mine
} 
So, any cause or effect is composed by the people and nature alike. People equally participate with plants and water in the composure of the morning's soft moisture which ultimately wraps them all alike, while the Wadi similar to its people "wake[s] up" to begin and share another new day with them. In another incident early in the novel, Munif reinforces an inseparable connection between the people and the animals of the Wadi and states that one could easily think of the people "as horses run and trained to the point of over leanness, but still strong, sturdy and beautiful" (9). Munif also explains that similar reactions are also experienced by the nature and the people of the Wadi. For instance, when heavy rains falls on the Wadi "[t]he happiness show[s] everywhere, in men and animals and even in harsh, unmoving nature" (64). Accordingly, when the Oil curse, upheavals the wadi, both the people and the other parts of nature suffer similar consequences. Munif explains that after the discovery of Oil, and after the Americans were present as a consequence, the Americans' "air-conditioned rooms whose thick curtains shut everything out: sunlight, dust, flies, and Arabs"(391),while the "roar' of the Oil machines was "frightening [Arab] men, animals, and birds" (68), alike. So, people and the components of nature are inseparable. In fact, throughout the novel, it is rarely that either the people or environmental nature is mentioned separately. Regardless of the effect or condition whether thick or thin, the people and their natural surroundings are facing the same thing.

It is actually important to note that this strong relationship between the natural environment and the people is presented through two major approaches in the Cities of Salt. The first approach could be seen through the humanization of nature in a number of places in the novel to the extent of portraying it as a mother-figure, whereas the second is the presentation of the people's life specifically interweaved within the two major components of the Arabian natural Oasis; the palm trees, and water. The humanization of the nature is found throughout the novel. The first few chapters, and specifically the first sentence in the Cities of Salt reinforce the importance of nature in the novel, the readers are introduced to the beautiful natural scene in Wadi al-Uyoun. "Wadi AL-Uyoun: AN OUTPOURING OF GREEN...as if it had burst from within the earth or fallen from the sky...It was one of those rare cases of nature expressing its genius and willfulness" (1). Having this "Wadi" in the heart of the oasis serves the image of considering it as a living character which also maintains the life of all of the other living creatures in the environment. In fact, the Wadi could be seen as a mother-figure to its inhabitants that "gives birth to them" and continues to nourish them and provides them and the palm trees alike with many elements of life. Munif describes the sprouting of the plants in the form of the human birth imagery while Miteb watches his garden bloom after the rain blessings. He states that:

it gave [Miteb] pleasure to watch the water drip into the earth to remain there. Then the earth began to do incredible, unfathomable things. . there was a prolonged tremor within the earth, like a convulsion, and the insides of the earth began to spill out... He had seen seedlings planted only a few weeks before pushing up forcibly through the soil, their small tips aloft, getting bigger by the moment... it was like the moment of man and woman's mating-like a moment of rapture" (65).

Munif had also already established the people's and palm trees inseparable connection earlier in the novel through the imagery of human birth and plant sprout and growth. In one of the conversations between Miteb and his son, Miteb points to one of the palm trees and explains to his son:

[t]hat tree, the fourth on the left, is just your age, boy. You grow every day, and it grows with you. Tomorrow you will plant a tree for your son, and he'll plant a tree for his son, and Wadi will get greener every day. People will keep coming to drink the water and hope never to die, and when they sit in the shade of the tree they'll say, 'May God show mercy to whoever planted the trees and the green plants" (48).

Furthermore, due to such a relation with nature, people like Miteb "feels more than any other time the bonds tying him to the land and palms and fig trees and to the people of the Wadi, too"(72) Indeed, stronger relations are built with other members of the Wadi because "the people [became] as if they were one family. It's true that family relationships of some kind or another brought people together here, but the relationships that dominated were stronger than those family ties" (72). The mother-figure nature made the people more related to each other. It could be said that the water of the Wadi that runs in the veins of palm trees, birds, animals, and the people have proved to be tighter and stronger than any other blood ties among the people of the Wadi.

Munif also links the Wadi's people to its water through the use of both simile and metaphor. He explains that "Wadi alUyon's people, like its waters, flooded out in times of overabundance: emigration had been a necessity for a long time. One day they would feel that there were too many of them for the wadi to support, and the young men able to travel would get ready to head out to new places to live and work" (5). In other places he describes the people's faces "flooded with life" (10). Munif further describes in the novel that after rainy seasons, in addition to "the abundant water that filled the three reservoirs and encircling streams the good years brought the waters which flowed down to where water was never expected to reach" (4) similarly, the people "would overdo their insistence that all travelers stay longer," and "[ $\mathrm{t}]$ heir generosity would reach the point of extravagance. Leading some travelers to consider them silly and rash people who never thought of tomorrow" (4). Accordingly, the metaphor is completed through stating that "during the years of drought," (4) people' generosity droughts and they drawback into their tents and withdraw themselves from contacting with the passing caravans. So, their generosity floats and droughts like and according to the Wadi's water. So, most of the first chapters of the novel sets the strong harmonious connection between the people and the environment to the 
extent that nature presented with human characteristics and people's life interweaved with the Wadi's palm trees and waters.

\section{The Humanized Resistance of the Environment}

Munif further reinforces the presentation of the environment as a humanized character that has been colonized by Oil by portraying its human-like resistance in the face of Oil's colonization. In fact, it is important to note that the first act of colonization was not evacuating the people but rather it was the uprooting of the palm trees. The Oil took over the place of the oasis's soil and water. Because the palm trees were the first to be destructed by Oil, they were the first to resist in face of the Oil extraction machines. Munif describes the scene of uprooting of the palm trees as "butchery" (106), and crazy massacre performed on humans and where the palm trees also resisted in a human-like manner. He states that that "trees shook violently and groaned before falling, cried for help, wailed, panicked, called out in helpless pain and then fell entreatingly to the ground, as if trying to snuggle into the earth to grow and spring forth alive again" (106). This scene also reinforces the previous point of the humanizing the Wadi and its earth as a "mother- figure" where both plants and people alike "snuggle into" its belly "to grow and spring forth alive" (106). This humanization is also further strengthened by Miteb al-Hathal's apology to the palm trees for not being able to answer their call for help and rescue. He was only able to tell them that he actually heard them plead by crying at them and at the Wadi "in a very harsh but pained voice: "I'm sorry. Wadi al-Uyon...I'm sorry" (106). Thus both the Wadi and the palm trees are considered humans to its people. They have always heard each other and talked to one another. In fact, this scene could be considered the most important one in the novel because the ecological destruction and physical death of nature ultimately coins the psychological death and cultural displacement of its people which is a result of one destructive force of Oil. In the Cities of Salt, the palm trees represent the body and the people present the soul, the destruction of one leads to the death of the other. In fact, Munif reinforces again this relationship and this unified fate twice in the same section. He explains that as the Americans "poured out like a band of devils. In a flash they headed for the machines with a speed and excitement that finally signaled that the end has come... This was the final, insane, accursed proclamation that everything had come to an end... For anyone who remembers those long-ago days, when a place called Wadi al-Uyoun used to exist, and a man named Miteb al- Hathal, and a brook, and trees..." $(105-106)^{2}$. This emphasis of the emerging death and end underpins that the human existence is linked with the ecological existence. The place and the man are one thing in Wadi al-Oyoun; the 'cutting/executing of the palm trees results in the death of the people's souls regardless of their survived living shallow bodies. Palm trees were not the only ones that resisted and mourned in a human-like way, other animals reacted similarly. People's most important animal companion in the desert; the camel participated in resisting and refusing the presence of Oil. Munif states that "[t]he camels constantly made chewing noises with their hips; he could see their shoulders ... sadder than any other camels [Fawaz] had ever seen , straining their tongues and throats as if cursing, and looking around them resentfully" (351).

Not only, did the environment resist in a human-like manner in the novel, but it indirectly resisted through its people nature-like responses to the Oil's colonization. Munif describes that Miteb al- Hathal was "shaking like a leaf and glancing about him like a wolf" (68), after seeing the Oil machines in the Wadi while his son "slept a little and ate like a frightened bird" (121). Women of the Wadi also reacted in a similar way to the point that Wadha, Miteb's wife, "now seemed like an old camel" (124). In fact, right after, the butchery of the Wadi's palm trees, Munif shows how Miteb decided to passively resist and leave the Wadi in reaction to this natural/human loss/death through many scenes including the following one: "Miteb al-Hathal rose on [his camal's] back like a huge tent, and then he looked like a cloud, and when he sped off he looked like a white bird, he faded from sight and grew smaller, dwindled and then disappeared" (107).So, Miteb is portrayed through a collective image of nature; as a tent, a cloud, and a white bird. All of which are parts of the Wadi's natural and environmental imagery. The environment's human-like resistance is further reinforced by Munif through the following scene towards the end of the novel:

Children returning from school to the western hill had seen men running toward Ibn Naffeh's house, and when they stopped to watch, they heard a piercing scream followed by flocks of white birds flying out of the windows and door. They were the largest birds they had ever seen. The birds sitting on the wall of the courtyard all fell of at the same moment and were eaten by circling dogs, who had been barking eerily (579).

So, Ibn Jaddan's death is accompanied by the death of the Wadi's birds, all at the same moment. Such inseparable connection to the environment is evident in many incidents of people's birth and death throughout the novel. So, the disappearance and death of man ultimately meant the ecological disappearance and death of the natural setting including the ones in the sky like clouds and birds and the ones on the land like camels and tents and vice versa.

Munif gives another example of the environment's human-like resistance in the following scene where he describes people's environmental-physical features and reactions after the destruction of the Wadi's environmental setting. He states that:

[b]eside the ruins on the broad plain [people] sat, determined to stay and wait. They moved slowly and mournfully, like windblown scarecrows made of rags and palm branches, moving and

\footnotetext{
${ }^{2}$ Emphasis is mine.
} 
then settling down gradually to become part of the boundless, dusty, motionless experience, now rising again and now reposing" (110).

Thus, again the existence of both man and nature are inseparable in the novel whether in physical shape or motion, and the disappearance of one means the fading away of the rest all at the same time. Miteb, when on his camel, didn't leave alone; the tent, the birds, and the clouds all left with him. All of which faded away after the death of the palm trees. The people also looked motionless like scarecrows made of the Wadi's dead palm branches.

The environment's resistance is further supported in the novel through several scenes of people's nature- like actions to reclaim their soil and place. So, not only did humans, birds, and animals fade away together, but they have also returned together to reclaim back their soil and place. Similar to animals, one of the men "stood like a wolf ready to spring" (102). Women like Wadha also spoke out and "the sounds that came out from her mouth were more like animal sounds or the groans of mourning, exactly like the clash of branches or the echo of a narrow valley. Like a strangled cat, she tried to talk" (130). So, not only did Wadha looked "like an old camel"(124), but other Wadi's wounded animals and broken branch trees wanted to talk and resist through her voice. Furthermore, Munif explains in the end of the novel that "the human waves plunged forth. The people later said that Fawaz al-Hathal and his brother Mugbel, who had arrived in Harran a few weeks before, were seen flying through the air like birds, crying, "we have come, here we are, Father! (615). The two brothers were not seen running or walking but instead flying like birds. The rest "ran like camels" (612). Munif also reinforces the inseparable connection and appearance between man and nature and states that:

[t]hose who arrived at the compound late said that they had seen from a far a man on a white camel pursuing the soldiers and firing at them...many of them said that the man was Miteb alHathal. Still others swore with absolute certainty that they saw a phantom shaped like a man flying above their heads, and it looked exactly like Mufaddi al- Jeddan (616).

It was hard to differentiate between the people and the environment they are in. It was hard to the extent that the people of the Wadi did not know whether those returning to reclaim the Wadi's soil were people, birds, or camels.

\section{The People's Cultural Dislocation:}

The environment's importance as a humanized mother-figure to the Wadi's people and their inseparable connection to it is further reinforced by Munif in the novel. Munif points out to the amount of cultural disorientation that is evident in several episodes throughout people's daily life in the Wadi after the presence of Oil and its colonization of their soil. The destruction or loss of any of the environmental surrounding ultimately meant the loss of the people's cultural identity despite the fact of them remaining in the same geographical place because their culture is an environmentalbased one. Rob Nixon refers to Rick Bass's essay "The unprotected Wilderness of the West," in which Bass wrote in defiance of Southern Utah's Red Rock country and declares that:

[the Red Rock country] is one of our greatest strengths as a country. Another is our imagination, our tendency to think rather than to accept -to challenge, to ask why and what if, to create rather than destroy. This questioning is a kind of wilderness, a kind of strength, that many have said is particularly American... To lose Uttah's wilderness would be strip westerners and all Americans of a raw and vital piece of our soul, our identity, and our ability to imagine... The print of a deer or lion in the sand, in an untouched country, as you sleep - it is these things that allow you, allow us, to continue being American rather than something else, anything else, everything else. (qtd in Nixon Environmentalism and Postcolonialism 237)

Munif raises a relevant point in the Cities of Salt when he sorrowfully asks one of the main important questions that the novel raises: "[h]ow is it possible for people and places to change so entirely that they lose any connection with what they used to be? Can a man adapt to new things and new places without losing a part of himself?" (134).Of course, the Wadi's people had to lose part of themselves because they no longer recognized the place they are in and no longer defined by it. Due to the Oil's colonization of the Wadi's soil many changes have taken place in the Wadi and consequently affected its people. For instance, after returning to the Wadi, Fawaz could not recognize the Wadi he once lived in to the extent that "it seemed to [him] a place he had never seen before. There was no trace of the wadi he had left behind; none of the old things remained. Even the fresh breezes that used to blow at this time of year had become hot and searing in daytime, and a bitter cold penetrated his bones late at night" (135). Not only did not Fawaz recognize the place, he could not recognize the people still remaining there "the men who had gathered there, he did not know from where, in their tents and wooden houses, were a bizarre mixture of humanity; they bore no resemblance to anything a man would recognize" (135). All what he saw was "strange and disgusting creatures filled with silence and sorrow" (136). To further remind the readers and reinforce of the strong connections between the Wadi and its people, Munif describes that one of the men that Fawaz had seen was like "a bird who had strayed away from the flock and lost his way, unable to stay where he was and powerless to resume the journey" (136). So, peoples' physical features were strongly defined and recognized by the Wadi's water, palm trees, birds, and other animals. Therefore, when all these components of the environment disappeared it was hard for Fawaz to recognize any of the people he met when he returned. He felt alienated to the extent to have never belonged to the Wadi. 
Since the Wadi's people's culture is an environmental-based one, Munif illustrates other psychological destructive changes that relate to the theme of cultural identity and belonging shaped by the environment. In fact, the connection among the Wadi's environment and its people is so evident to any outsider. Munif reveals that the Americans noted the importance of living in the desert to be able to understand the culture of its people. In one episodes of the novel an American worker said to another that:

You can't explain the sadness of these people's lives unless you've known the desert and lived in it. This damned desert breeds nothing but this kind of people and the kinds of animals we saw on our way here...Everything about them is wrapped up, layers upon layers, just like the desert under their feet! ... They're like animals jostling each other and moving around in this primitive way to express their happiness. Imagine! (267).

These previous lines of the novel again prove that the Wadi and the desert are mother-figures that "breed" people and animals alike. Thus it could be argued that any change of the Wadi's and desert's soil ultimately changes the way they "breed" the people whether physically or culturally. Munif points in the Cities of Salt that as a consequence of the Oil discovery in the Wadi and the fact that many people had no choice but to either stay and work in the newly established Oil Company or travel and live elsewhere away from their only home. Many of them had chosen to stay out of necessity.In order to fully investigate the cultural dislocation, it is important to note that in the Arabic culture, men and women are identified by the name of their fathers after their first names. So, Shaalan bin Miteb means Shaalan the son of Miteb. Similarly, Mizna bint Hathal means Mizna the daughter of the Hathal. Fathers and mothers are also called and identified by the names of their first son. So, Abu Fawaz means the father of Fawaz and "Umm fawaz" means the mother of Fawaz. Through this method of identifying, naming, and calling the Arab people, we can see that Arabs are identified by their connections to others since they are rarely called by their first names especially when they become mothers and fathers. However, after working in the Oil Company, the Wadi's people were identified differently. Shaalan is no longer identified by the name of his father; instead he is called now "Company Shaalan" or "American Shaalan" (134). Munif also further reinforces and reminds the readers of the (lost) once strong connection between the people of the Wadi and the environment through explaining that "Shaalan planted himself in Wadi Al-Uyon not only like the palm trees that had filled the wadi in times gone by"(134), but particularly the one planted by his father when he was born. However, due to the Oil's colonization Shaalan was now planted "like one of the iron columns that now stood everywhere, and within a short time he changed very much indeed" (134). Instead of having ties with the palm trees that had reached the level of being humanized throughout the novel, people are now being culturally disoriented and environmentally dislocated to the extent of being dehumanized and presented to resemble the non-living "iron columns" which were forcedly dug to replace the uprooted palm trees. People's identities had been stripped away from them as well as that they did not longer belong to the Wadi but rather to the Oil Company. The people's eco-cultural identity became a petroleum- based one. Munif states that after seeing the Oil Company built in the Wadi "Fawaz knew that night, that what had happened was not just the loss of a place called Wadi al-Uyoun, nor any loss that a man could describe or grow accustomed to. He realized that it was breaking off, like death that nothing and no one could ever heal" (121). Indeed, dramatic shifts and changes had taken place; before the oil discovery, nature was humanized whereas people themselves were dehumanized after the presence of Oil; as if life itself has ended in the Wadi.

Not only, were the people striped from their eco-cultural identity and their ties with the palm trees were cut, but they were also forced to break their connection with another important natural component of their environment. The people were asked to give up their camels because "they are of no use here [in the American Harran]" (CS186). In fact, "they were being asked to give up the most precious they owned" (186). It was a big sacrifice they were forced to carry out. As a result, all ties with the nature that have always identified the people identity and pinned their belonging to their culture have been cut and dissolved by the ecological destruction of the Wadi. Again this point reinforces that the people and their natural surroundings are one. As previously stated, the Wadi's people stand for the soul which lives in the environment's body made of palm trees, animals, birds all of which are connected by the Wadi's water that runs through their veins and roots. Thus, the Cities of Salt traces the beginning of the petroleum culture that resulted due the ecological destruction which have dislocated and dissolved the Wadi's people's eco-cultural identity. Upon the Oil discovery in the Wadi , Munif states that "Within days everything in the Wadi changed men, animals, and nature" (67). Referring to this change Nixon explains "how easily" such changes and discoveries "can destroy the delicate, always mutable, mesh between cultural traditions, ... and ecosystems" (Nixon 243). Water ties have been cut which have always existed and connected the man and nature in the Wadi. Although, the Wadi's people continued to live in the same geographical space, the ecological destruction has heavily weighed upon the cultural identity and belonging to the extent of dislocation.

\section{Conclusion}

From what has been stated above, Munif in the Cities of Salt was able to link the areas of postcolonialism, environmentalism, and the Oil discovery by humanizing the environment and tracing the colonization of its soil by Oil and it forces, and by presenting the environment's human- like resistance through different episodes of personification and through the Wadi's people's environmental- like reactions. Furthermore, due to the people's eco-cultural based identity Munif presented the postcolonial effect of the emerging petroleum culture which was a result of the destruction of the Wadi's ecosystem. 
References

Boullata, I. J. (1998). Social Change in Munif's Cities of Salt. Edebiyat 8.2: 191-215. Print.

McLarney, E. (2009). Empire of the Machine: Oil in the Arabic Novel. Boundary 2, 36(2), 177-198.

Munif, A. R. (1987). Cities of Salt. Trans. Peter Theroux. New York: Random House, Print.

Nixon, R. (2005). Environmentalism and Postcolonialism. Postcolonial Studies and Beyond. Ed. Ania Loomba, Suvir Kaul, Matti Bunzl, et al. Durham: Duke UP. 233-51. Print.

---. (2011). Slow Violence and the Environmentalism of the Poor. Cambridge, MA: Harvard UP, Print.

Shannon, L., Vin N., Ken Hiltner, Saree M., Ziser M, and Szema I. (2011) Literature in the Ages of Wood, Tallow, Coal, Whale Oil, Gasoline, Atomic Power, and Other Energy. Editorial.PMLA 126.2: 305-326. Print.

“Wadi” Def. Oxford Dictionaries Online. Oxford UP, n.d. Web. 21 Aug. 2015.

Walonen, M. K. (2012). The Black and Cruel Demon" and Its Transformations of Space: Toward A Comparative Study of the World Literature of Oil and Place. Interdisciplinary Literary Studies, 14(1). 